\title{
INFERIOR FRACTURE DISLOCATION OF THE SHOULDER IN A FOUR YEAR OLD GIRL: REPORT OF A RARE CASE
}

\author{
Chidanand K. J. C1 ${ }^{1}$ Avinash Parthasarathy², Prakashappa T. $\mathrm{H}^{3}$
}

\section{HOW TO CITE THIS ARTICLE:}

Chidanand K. J. C, Avinash Parthasarathy, Prakashappa T. H. "Inferior Fracture Dislocation of the Shoulder in a Four Year Old Girl: Report of a Rare Case". Journal of Evolution of Medical and Dental Sciences 2014; Vol. 3, Issue 20, May 19; Page: 5541-5545, DOI: 10.14260/jemds/2014/2626

ABSTRACT: Fracture-dislocations of the shoulder are extremely rare in children. We report a case of inferior fracture-dislocation of the proximal humeral epiphysis in a 4-year-old girl. A Pubmed search did not reveal such a dislocation in children less than five years of age. Closed reduction is not always possible when there is a significant displacement or soft tissue interposition. The inferior fracturedislocation was successfully treated by an open reduction and Kirschner wire fixation.

KEYWORDS: Shoulder fracture dislocation, inferior, child.

INTRODUCTION: Fracture-dislocations of the shoulder are extremely rare in children. A literature search revealed only few reports of fracture-dislocation of the shoulder in a children younger than five years of age.1,4 However, there have not been any reports of inferior fracture dislocations in which the mid-point of the humeral head lies at the inferior lip of the glenoid, rather than at its center. ${ }^{5}$ In the presence of severely displaced fracture fragments, closed reduction may not be feasible or successful. ${ }^{6}$ There have been successful reports of open reduction and internal fixation (ORIF) in similar cases. ${ }^{1,4}$

CASE REPORT: A four year old girl presented with a history of fall from a height of 10-12 feet and injury to the right shoulder. She complained of pain in the right shoulder. Physical examination revealed a swollen and tender right shoulder. Her arm was in slight abduction and external rotation. The patient could not move her right shoulder and did not allow any passive movement of her right upper limb. There was obliteration of the normal shoulder contour with deformity and shortening of the arm. The neurologic and vascular examinations of the right extremity were normal. Radiographs showed epiphyseal separation of the right proximal humerus, Salter-Harris type III, and inferior dislocation of the glenohumeral joint into the subglenoid region (Figure 1).

Initially, the right shoulder was immobilized with a $U$ slab and then posted for closed reduction under fluoroscopic control under general anesthesia. Since this proved to be difficult we went ahead with an open reduction and internal fixation. We used the deltopectoral approach, and noted a capsular interposition between the fracture fragments. Percutaneous fixation with two Kirschner wires inserted from the distal to the proximal end was performed (Figure 2). The shoulder was immobilized for three weeks with an arm pouch sling.

After four weeks the Kirschner wires were removed (Figure 3) and the patient was advised physiotherapy. By six weeks the patient had full range of shoulder movements (Figure 4 A-D) and radiologically there was neither a growth disturbance nor avascular changes in the head of the humerus (Figure 5). There were no episodes of recurrent dislocation during a one year follow up. The length of the right humerus was normal with no length discrepancy when compared to the 
contralateral humerus. The radiographs showed an open epiphyseal plate with near complete remodeling of the fracture at the time of last follow up.

DISCUSSION: Shoulder-dislocations are rare in children with Rowe documenting a 1.6\% incidence rate in children younger than 10 years of age. ${ }^{7}$ Isolated proximal humeral fractures are more common in young children and they tend to occur through the growth plate due to its relative weakness. Sanders et al. ${ }^{8}$ reported a series of 44 patients with shoulder-dislocations and found that a combination of shoulder dislocation and proximal humeral physeal fracture was extremely rare in children younger than 5 years. However, as the child reaches adolescence the incidence of shoulder dislocation increases.

Of the four reported cases of fracture dislocation in children less than five years, two cases underwent open reduction and percutaneous Kirschner wire fixation, ${ }^{1,4}$ while the other two were treated with closed reduction and percutaneous Kirschner wire fixation. ${ }^{2,3}$ Nicastro and Adair ${ }^{1}$ documented a case of a 32-month-old child with epiphyseal separation and anterior dislocation of the proximal humeral epiphysis and opined that the fracture fragment penetrating through the joint capsule could prevent reduction by closed means. Gupta et al. ${ }^{3}$

Concluded that closed reduction should be attempted in all cases of fracture dislocations of the shoulder as a partially intact periosteal sleeve with some continuity with the capsule of the glenohumeral joint and non-penetration of the proximal fragment through the glenohumeral capsule can allow reduction by closed means. Jhongun et al. ${ }^{4}$

Reported a case of severely displaced fracture dislocation of the shoulder in a five year old girl who was treated with ORIF. Their initial attempt of closed reduction failed and attributed the severity of displacement coupled with periosteal interposition as the reason for failure of closed reduction.

With increasing severity of displacement there is a higher chance of capsular penetration by the proximal fragment and soft tissue interposition between the fracture fragments. Open reduction is therefore indicated for severely displaced and neurovascular-threatening injuries along with interposed periosteum, deltoid, capsule or the long head of biceps. ${ }^{4}$

There is always a valid concern that open reduction may disturb the vascularity of the epiphysis and therefore retard growth. Wang et al. ${ }^{9}$ Report a successful ORIF of a Salter-Harris type III anterior fracture-dislocation of the proximal humerus in a 10-year-old boy for who they performed bone scans.

The scans at initial hospitalization revealed devascularization of the humeral head but subsequent revascularization at the 2-year follow-up. There was also no growth retardation in this child post treatment.

CONCLUSION: Open reduction with internal fixation can be the first choice in significantly displaced fracture dislocations such as an inferior fracture dislocation of the shoulder. Successful outcomes can be obtained without endangering neurovascular structures.

\section{REFERENCES:}

1. Nicastro JF, Adair DM. Fracture-dislocation of the shoulder in a 32-month-old child. J Pediatr Orthop. 1982; 2: 427-429 


\section{CASE REPORT}

2. Winmoon C, Sathira-Angkura V, Kunakornsawat S, Prasartritha T. Fracture-dislocation of the glenohumeral joint in a 2-year-old child: case report. J Trauma. 2003 Feb; 54 (2):372-5.

3. Gupta R, Singh A, Singh KK, Vohra R. Idiopathic bilateral gluteus maximus contracture in adolescent female: A case report. Journal of Orthopaedic Case Reports 2013 Jan-March;3 (1): 26-28.

4. Ji JH, Shafi M, Park SE, Park PY. A severely displaced metaphyseal fracture of the proximal humerus with dislocation of the shoulder in a child. Chin J Traumatol. 2014 ; 17 (1):54-6.

5. Do T, Kellar K. Transitory inferior dislocation of the shoulder in a child after shoulder injury: a case report and treatment results. Iowa Orthop J. 2004; 24:119-22.

6. Di Gennaro GL, Spina M, Lampasi M, Libri R, Donzelli O. Fractures of the proximal humerus in children. Chir Organi Mov. 2008 Sep; 92 (2):89-95.

7. Rowe CR. Prognosis in dislocations of the shoulder. J Bone Joint Surg Am. 1956; 38: 957-977

8. Sanders JO, Rockwood CA, Curtis RJ. Fractures and dislocations of the humeral shaft and shoulder. In: Rockwood CA, Wilkins KE, Beaty JH, eds. Fractures in Children. 4th ed. Philadelphia: Lippincott-Raven; 1996: 905-1020

9. Wang P, Koval KJ, Lehman W, Strongwater A Grant A, Zuckerman JD. Salter-Harris type III fracture-dislocation of the proximal humerus. J Pediatr Orthop B 1997 Jul; 6 (3):219-22.

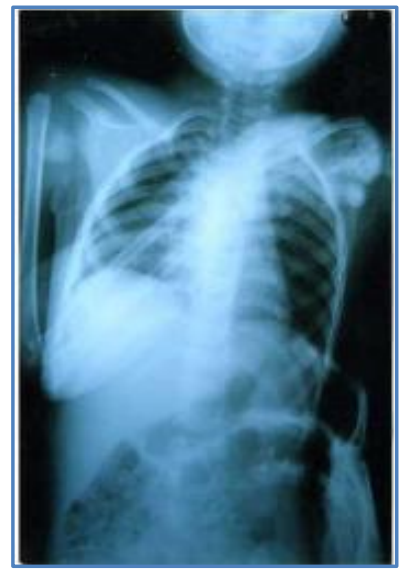

Figure 1: Radiograph showing fracture dislocation of proximal humerus, Salter-Harris Type III

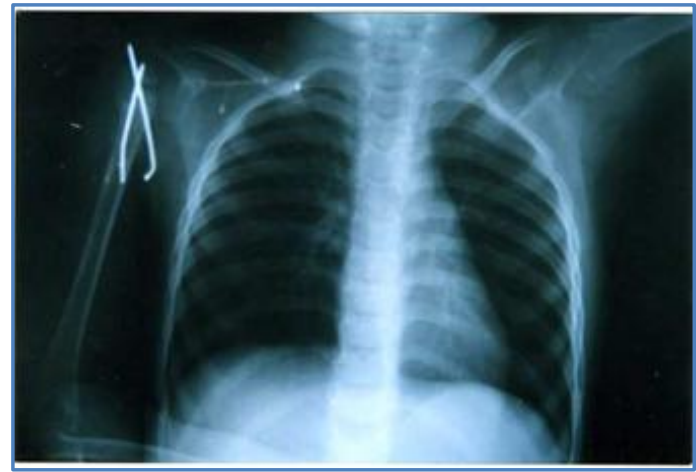

Figure 2: Immediate post- operative radiograph showing the reduced fracturedislocation and two Kirschner wires 


\section{CASE REPORT}

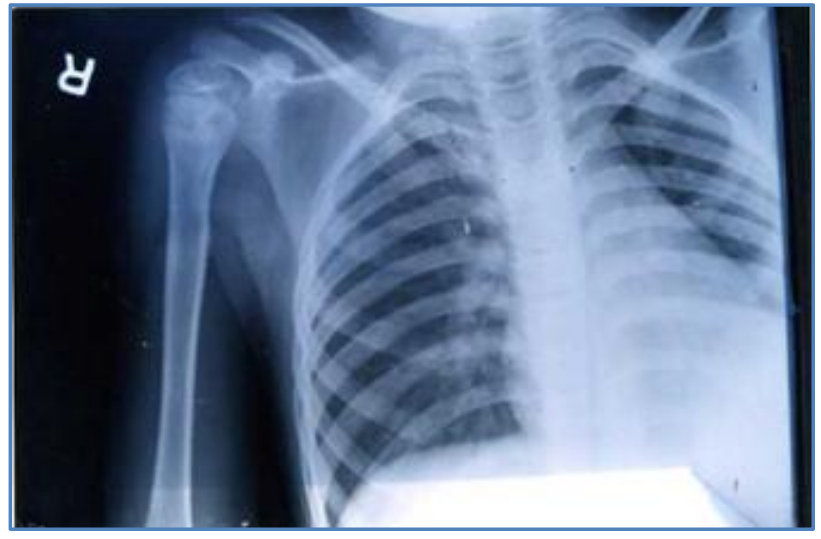

\section{Figure 3: Follow up radiograph after Kirschner wire removal}

Figure 4: A, B, C, D - Range of movements - flexion, abduction, rotations and shoulder contour:

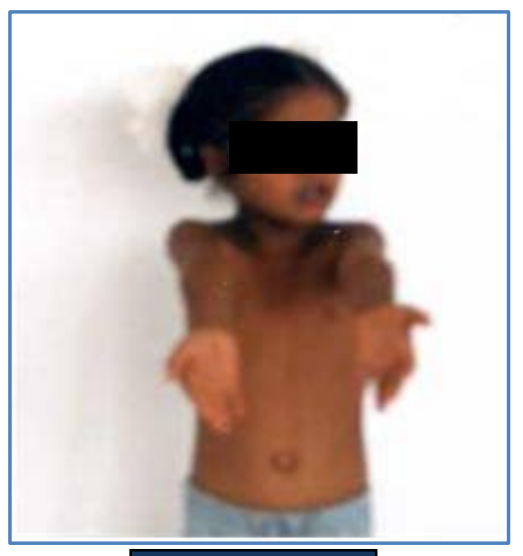

Figure 4A

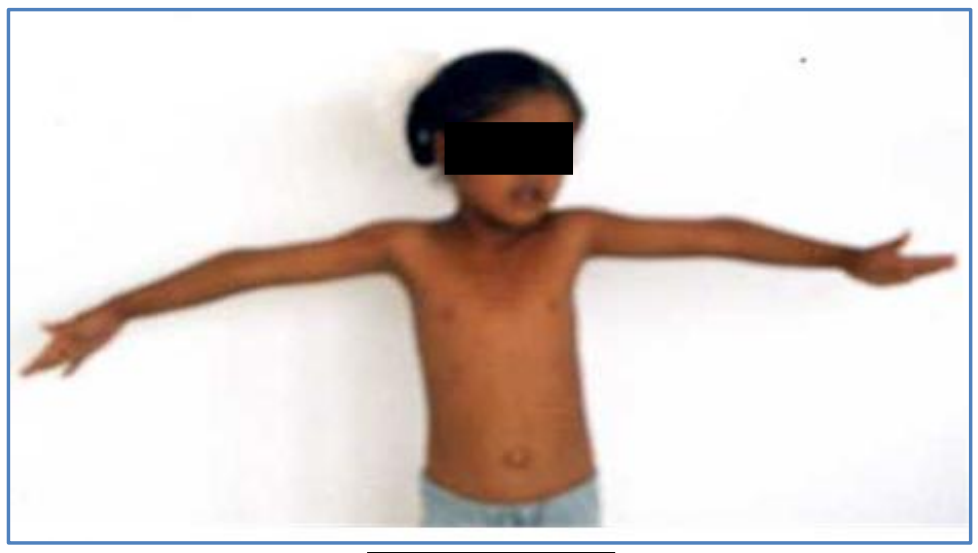

Figure 4B

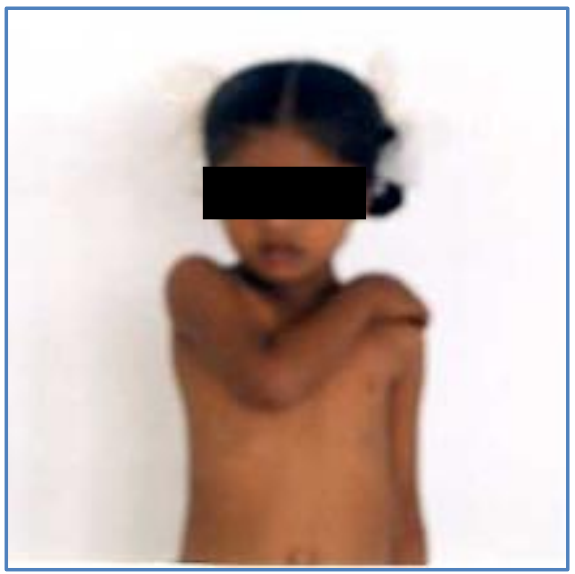

Figure 4C

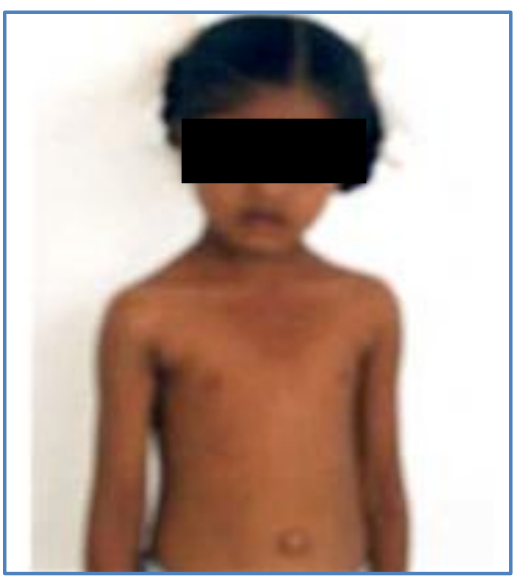

Figure 4C 


\section{CASE REPORT}

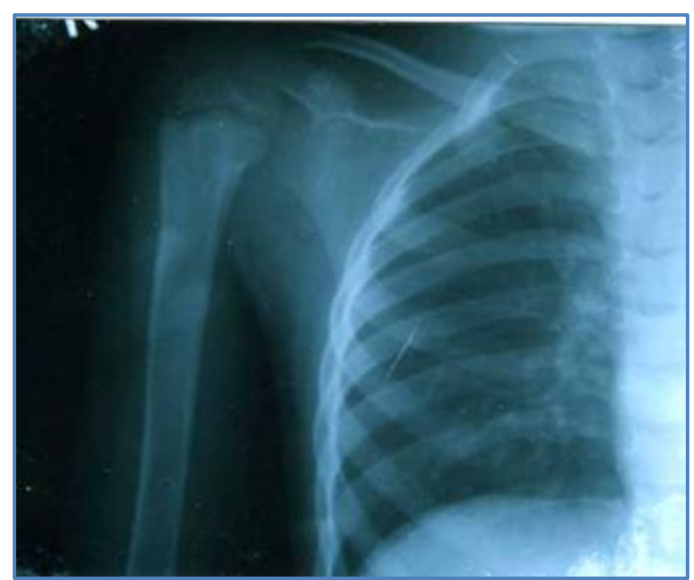

\section{Figure 5: Follow up radiograph showing complete} remodeling and no avascular changes

\section{AUTHORS:}

1. Chidanand K. J. C.

2. Avinash Parthasarathy

3. Prakashappa T. H.

\section{PARTICULARS OF CONTRIBUTORS:}

1. Assistant Professor, Department of Orthopaedics, Sanjay Gandhi Institute of Trauma and Orthopaedics, Byrasandra, Bangalore.

2. Assistant Professor, Department of Orthopaedics, Sanjay Gandhi Institute of Trauma and Orthopaedics, Byrasandra, Bangalore.

3. Professor, Department of Orthopaedics, Sanjay Gandhi Institute of Trauma and Orthopaedics, Byrasandra, Bangalore.

\section{NAME ADDRESS EMAIL ID OF THE} CORRESPONDING AUTHOR:

Dr. Avinash Parthasarathy, Assistant Professor, Department of Orthopaedics, Sanjay Gandhi Institute of Trauma and Orthopedics, Byrasandra, Jayanagar IV 'T’ Block, Bangalore - 560011. Email: dravinash@hotmail.com

Date of Submission: 25/04/2014. Date of Peer Review: 26/04/2014. Date of Acceptance: 08/05/2014. Date of Publishing: 19/05/2014. 